\title{
Assessment of in vitro Antibacterial and Antifungal Activities of Leaf Extracts of Melia azedarach Linn
}

\author{
A. K. KATHIRESHAN*, T. PRIYA, K. DORIS JASMINE, G. GAYATHRI AND M. R. RAMESH KUMAR ${ }^{1}$ \\ Department of Microbiology, School of Life Sciences, VELS University, Chennai-600 117, ${ }^{1}$ Infectious Diseases Laboratory, \\ YR Gaitonde Centre for AIDS Research and Education, Voluntary Health Services Hospital Campus, Chennai-600 113, India
}

Kathireshan et al.: Antimicrobial activity of Melia azedarach Linn.

\begin{abstract}
The present study was aimed to analyse in vitro, the antibacterial and antifungal activities of the leaf extracts of Melia azedarach. Leaves were extracted using different solvents such as ethanol, methanol and acetone by hot percolation method. Antibacterial and antifungal activity was measured using agar well diffusion assay and broth microdilution methods, respectively against different pathogenic bacteria and fungi. Thin-layer chromatography-directed bioautography was performed to determine the phytochemicals of the extracts and their antimicrobial activity. The gas chromatography-mass spectroscopy analysis was performed for the isolated active components exhibited antimicrobial activity. Among the various extracts tested, ethanol extract showed significant antimicrobial activity and exhibited zone of inhibition of $16 \mathrm{~mm}$ against Bacillus subtilis, $15 \mathrm{~mm}$ against Staphylococcus aureus, $14 \mathrm{~mm}$ against both Vibrio cholerae and Klebsiella pneumoniae, $12 \mathrm{~mm}$ against both Escherichia coli and Pseudomonas aeruginosa. The ethanol extract showed minimum inhibitory concentration of $250 \mu \mathrm{g} / \mathrm{ml}$ against both Aspergillus niger and Candida albicans. Phytocompounds in the ethanol extract were separated using TLC chromatogram and it showed seven spots. The bioautography of TLC chromatogram showed single band exhibited antibacterial activity and phytocompound from this band was isolated and identified as 5,6,7,8-tetrahydro-1,2,4-benzotriazine-3amine using gas chromatography-mass spectroscopy analyses. The ethanol extract of leaf of Melia azedarach exhibited significant antimicrobial activity and the compound 5,6,7,8-tetrahydro-1,2,4-benzotriazine-3amine might be responsible for antimicrobial activity.
\end{abstract}

Key words: Melia azedarach, Thin-layer chromatography-directed bioautography, Escherichia coli, antibacterial activity

Medicinal plants are locally used in the treatment of various infections caused by bacteria, virus, fungi and parasites. Plant-derived medicines are widely used because these are relatively safer than the synthetic medicines, easily available and cheaper ${ }^{[1]}$. Many plant species have been evaluated for their antimicrobial activity in the past 20 years ${ }^{[2]}$. According to the World Health Organization (WHO), about $80 \%$ of individuals from developing countries are using traditional medicines and about 80000 species of plants are utilized for treating various diseases in different systems of Indian medicines. Since 1990s there has been a growing shift in interest towards plants as significant sources for new pharmaceuticals. As per WHO report, $80 \%$ of the world population, presently using herbal medicine for some aspects of primary human health care ${ }^{[3]}$. With the advancement of modern medicinal technology, it is now easier to identify the specific plant constituents and assess their potential antimicrobial activity. Many herbs contain dozens of active constituents that combine to give

${ }^{*}$ Address for correspondence E-mail: kathireshanak@gmail.com the therapeutic value of the medical plants. Currently, microbial resistance to antibiotics has become a global concern and the clinical efficacy of many existing antibiotics is being threatened by the emergence of multidrug resistant pathogens ${ }^{[4,5]}$. Since the last decade, the rise in the failure of chemotherapeutics and antibiotic resistance exhibited by pathogenic microbes has led to the screening of several medicinal plants for their potential antimicrobial activity ${ }^{[1,6]}$. There is a continuous and urgent need to discover new antimicrobial compounds with diverse chemical structures and novel mechanisms of action for new and re-emerging infectious diseases ${ }^{[7]}$.

Melia azderach (family: Meliaceae) is one of the most useful medicinal plants in traditional system of

This is an open access article distributed under the terms of the Creative Commons Attribution-NonCommercial-ShareAlike 3.0 License, which allows others to remix, tweak, and build upon the work non-commercially, as long as the author is credited and the new creations are licensed under the identical terms

Accepted 27 January 2019

Revised 24 June 2018

Received 05 May 2017

Indian J Pharm Sci 2019;81(2):380-384 
medicine in India. $M$. azedarach is native to tropical Asia and it is wide spread in most of the tropical and sub-tropical regions. The leaves of $M$. azedarach are used in the treatment of leprosy, scrofula, anthelmintic, antilithic and diuretic. The fresh leaf extract is used as mouth wash for gingivitis and applied externally for burns. The seed oil is the most active medicinal product used as an antiseptic for sores and ulcers ${ }^{[8,9]}$. In this study, an attempt was made to analyse the antimicrobial activity of leaves of $M$. azedarach against selected bacterial and fungal pathogens in vitro followed by identification of active molecules in the extracts using thin-layer chromatography-directed bioautography (TLC-DB) and gas chromatography and mass spectroscopy analyses.

Fresh leaves of $M$. azedarach were collected from Nanmangalam, Chennai, India in polythene bags. On the same day, the leaves were washed using doubledistilled water and shade-dried at room temperature. The dried leaves were coarsely powdered in a mechanical grinder and weighed. A Soxhlet extractor was filled with $100 \mathrm{~g}$ of leaf powder of M. azedarach, the round bottomed flask was loaded with 21 solvent and was allowed to run for $72 \mathrm{~h}$. The solvents used for extraction were ethanol, methanol and acetone. The extracts obtained in this method were distilled, concentrated and stored in sterile vials at $-20^{\circ}$ for further use.

Antibacterial activity of leaf extracts was evaluated using agar well diffusion method ${ }^{[10]}$. About $20 \mathrm{ml}$ of Mueller-Hinton agar (MHA; HiMedia, India) medium was poured into sterile Petri plates and these plates were allowed to solidify. About $6 \mathrm{~h}$ young cultures of bacteria were adjusted to 0.5 scale of McFarland standard and the lawn culture of the test organisms was made on MHA plate using sterile cotton swabs. After $5 \mathrm{~min}, 5 \mathrm{~mm}$ diameter wells were made on the agar surface using a sterile cork borer. The extracts were dissolved in dimethyl sulfoxide (DMSO) and loaded into the wells with concentrations of 50, 100, 150 and $200 \mu \mathrm{g} / \mathrm{ml}$. Bacterial cultures of Staphylococcus aureus, Bacillus subtilis, Vibrio cholerae, Escherichia coli, Pseudomonas aeruginosa and Klebsiella pneumonia and fungal cultures of Aspergillus niger and Candida albicans were used in this study and these cultures were obtained from the Department of Microbiology, School of Life Sciences, VELS University, Chennai, India. For the antibacterial assay the Escherichia coli ATCC 25922 strain was used as a control organism. The plates were incubated at $37^{\circ}$ for $24 \mathrm{~h}$ and the antibacterial activity of the extracts was determined by measuring the zones of inhibition. Amikacin $(30 \mu \mathrm{g})$ was used as a standard drug and DMSO was used as a solvent control while performing the antimicrobial screening.

Antifungal activity of the extracts of $M$. azedarach was screened using broth microdilution method according to CLSI guidelines. Roswell Park Memorial institute (RPMI-1640) medium was used with L-glutamine buffered to $\mathrm{pH} 7.0$ with $0.165 \mathrm{M}$ morpholine propane sulfonic acid supplemented with $2 \%$ glucose. The prepared extracts were dissolved in DMSO and various dilutions from 0.4 to $250 \mu \mathrm{g} / \mathrm{ml}$ were prepared. RPMI medium was added to the wells from 1 to 10 and the diluted leaf extracts were added in the respective wells. Fifty microlitres of fungal suspension was prepared in $0.85 \%$ saline, with an optical density (OD) equivalent to 0.5 scales McFarland standard. This fungal suspension was inoculated into each respective well in the microtitre plate. Control wells contained inoculum without drug and drug without inoculum. Amphotericin $\mathrm{B}$ was diluted in DMSO and was used as a standard drug. The plates were incubated with agitation at $37^{\circ}$ for $24 \mathrm{~h}$ for Candida albicans and Aspergillus niger. OD values of wells were read at $490 \mathrm{~nm}$ in a spectrophotometer. The minimum inhibitory concentration (MIC) was defined as the lowest concentration that exhibited $90 \%$ inhibition of growth at which there is no visible fungal growth $^{[11]}$.

For TLC analysis, the plate with aluminium support silica gel 60F254, 10×10 cm (Merck, Germany) was cut with ordinary household scissors. Plate markings were made with soft carbon pencil. Various solvent systems were analysed and fixed with silica gel for plate preparation. The plate impregnated by dipping into chloroform-methanol $(9: 1)$ for $5 \mathrm{~s}$ followed by drying at room temperature for $1 \mathrm{~h}$. About $5 \mu \mathrm{l}$ of sample was loaded on the TLC plate using glass capillaries at a distance of $1 \mathrm{~cm}$. After presaturation of TLC plate with solvents, the TLC plate was placed in twin trough chamber with chloroform-methanol (9:1) as a mobile phase for $20 \mathrm{~min}$ for the separation of phytocompounds. The plates were photographed under white light, UV 254 and UV $365 \mathrm{~nm}$. The $\mathrm{R}_{f}$ value of the movement of phytocompounds was detected using the following formula, $\mathrm{R}_{f}=$ distance travelled by solute/distance travelled by solvent. The developed TLC chromatogram was used for bioautography. The TLC chromatogram was placed on a sterile Petri plate and about $20 \mathrm{ml}$ of molten MHA plate was poured and 
then Bacillus subtilis was swabbed on the agar plate using a sterile cotton swab. After $24 \mathrm{~h}$ of incubation the plates were observed for the zone of inhibition around the bands ${ }^{[12]}$.

An Agilent 6890 gas chromatograph was equipped with a straight deactivated $2 \mathrm{~mm}$ direct injector liner and a 15 m Alltech EC-5 column $(250 \mu$ ID; film thickness of $0.25 \mu$ ). A split injection was used for sample introduction and the split ratio was set to $10: 1$. The oven temperature was programmed to start at $35^{\circ}$, held for $2 \mathrm{~min}$, then ramp at $20^{\circ} / \mathrm{min}$ to $300^{\circ}$ and held for $5 \mathrm{~min}$. The helium carrier gas was set to $2 \mathrm{ml} / \mathrm{min}$ of flow rate (constant flow mode). A Jeol GCmate II Benchtop double-focusing magnetic sector mass spectrometer operating in electron ionization mode with TSS- $2000^{1}$ software was used for all analyses. Lowresolution mass spectra was acquired at a resolving power of 1000 (20\% height definition) and scanning from $\mathrm{m} / \mathrm{z} 25$ to 700 at $0.3 \mathrm{~s}$ per scan with a $0.2 \mathrm{~s}$ interscan delay. High resolution mass spectra were acquired at a resolving power of 5000 (20\% height definition) and scanning the magnet from $\mathrm{m} / \mathrm{z} 65$ to 750 at $1 \mathrm{~s}$ per scan. Identification of the components of the purified compounds was made by matching their recorded spectra with the data bank mass spectra of NIST library V 11 provided with the instrument's software.

Ethanol, methanol and acetone extracts of leaves of $M$. azedarach were tested against selected bacterial and fungal pathogens. In this study, it was found that the ethanol extract showed significant antimicrobial activity and other extracts such as methanol and acetone showed very less activity even at highest concentration tested, hence results for methanol and acetone were not reported in this study. Among the bacteria, the ethanol extract showed the zones of inhibition of 10 , 12,14 and $16 \mathrm{~mm}$ against $B$. subtilis followed by 9 , 10,12 and $15 \mathrm{~mm}$ against $S$. aureus, 9, 11, 12 and $14 \mathrm{~mm}$ against $V$. cholerae, 8, 9, 11 and $14 \mathrm{~mm}$ against $K$. pneumoniae, 7, 8, 10 and $12 \mathrm{~mm}$ against both $E$. coli and $P$. aeruginosa at concentrations of 50, 100, 150 and $200 \mu \mathrm{g} / \mathrm{ml}$, respectively (fig. 1 and Table 1). Ethanol extract of leaves of $M$. azedarach exhibited antifungal activity with a MIC value of $250 \mu \mathrm{g} / \mathrm{ml}$ against both $C$. albicans and $A$. niger.

The TLC chromatogram of ethanol extract of $M$. azedarach showed 7 bands with $\mathrm{R}_{f}$ values of 0.95 , $0.92,0.79,0.70,0.33$ and 0.16 . Out of the 7 bands on the TLC plate, the band with the $\mathrm{R}_{f}$ value of 0.79 exhibited

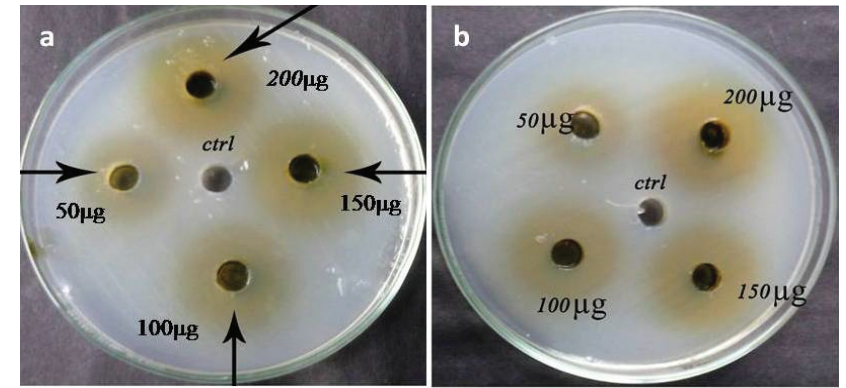

Fig. 1: Antibacterial activity of ethanol extract of leaf of Melia azedarach

$\mathbf{a}=$ Escherichia coli $; \mathbf{b}=$ Pseudomonas aeruginosa

TABLE 1: ANTIBACTERIAL ACTIVITY OF ETHANOL EXTRACT OF LEAVES OF MELIA AZEDARACH LINN

\begin{tabular}{lcccc}
\hline & \multicolumn{4}{c}{ Zone of inhibition (mm) } \\
\cline { 2 - 5 } Organisms & $\begin{array}{c}50 \\
\mu \mathrm{g} / \mathrm{ml}\end{array}$ & $\begin{array}{c}100 \\
\mu \mathrm{g} / \mathrm{ml}\end{array}$ & $\begin{array}{c}150 \\
\mu \mathrm{g} / \mathrm{ml}\end{array}$ & $\begin{array}{c}200 \\
\mu \mathrm{g} / \mathrm{ml}\end{array}$ \\
\hline $\begin{array}{l}\text { Escherichia coli } \\
\begin{array}{l}7.3 \pm 0.2 \\
\text { Pseudomonas }\end{array}\end{array}$ & $8.1 \pm 0.19$ & $10.3 \pm 0.04$ & $12.4 \pm 0.37$ \\
$\begin{array}{l}\text { aeruginosa } \\
\text { Vibrio cholerae }\end{array}$ & $9.1 \pm 0.10$ & $11.1 \pm 0.03$ & $12.1 \pm 0.46$ & $14.6 \pm 0.09$ \\
$\begin{array}{l}\text { Bacillus subtilis } \\
\text { Staphylococcus }\end{array}$ & $10.4 \pm 0.36$ & $12.1 \pm 0.41$ & $14.5 \pm 0.11$ & $16.1 \pm 0.51$ \\
$\begin{array}{l}\text { aureus } \\
\text { Klebsiella }\end{array}$ & $9.2 \pm 0.70$ & $10.2 \pm 0.27$ & $12.1 \pm 0.31$ & $15.1 \pm 0.83$ \\
pneumoniae & $8.3 \pm 0.44$ & $9.3 \pm 0.61$ & $11.4 \pm 0.61$ & $14.2 \pm 0.25$ \\
\hline
\end{tabular}

antibacterial activity against $B$. subtilis. The active band was scrapped and subjected to gas chromatographymass spectrometry (GC-MS) analysis. The GC-MS profile of the active band showed the presence of only one compound. The scanned mass spectrum revealed that the active compound showed highest match in the NIST database with 5,6,7,8-tetrahydro-1,2,4benzotriazine-3-aminecompound (fig. 2).

Currently many studies reported isolation of active compounds from crude extracts of medicinal plants and it was widely observed and accepted that the medicinal value lies in the phytocompounds present in the plants. Ayurveda, Siddha and Unani were the traditional health care systems in India. India is one of the important countries rich in herbal medicinal plants, with diverse ecosystems. In developed countries, the demand for herbal medicines is growing rapidly as it is gaining good acceptance, because of better action and safety profile. Medicinal plants have traditionally occupied an important position in the lives of rural and tribal people. The aromatic plants and aromatic chemicals play a vital role directly as well as indirectly in the day to day life of man since its appearance on the earth ${ }^{[13]}$. 


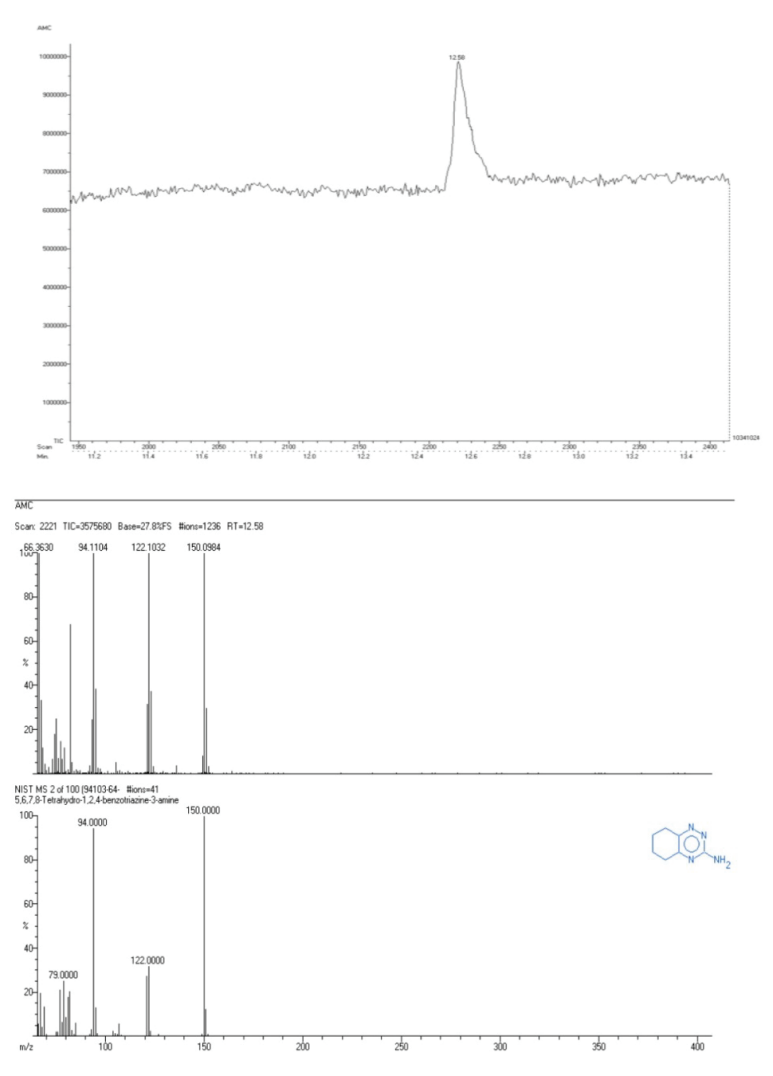

Fig. 2: Gas chromatography-mass spectroscopy analyses

In the present study, the ethanol extract of leaves of $M$. azedarach showed antimicrobial activity against $B$. subtilis, $S$. aureus, E. coli, $K$. pneumoniae, $P$. aeruginosa, $A$. niger and $C$. albicans. The finding of this study revealed that the leaves of $M$. azedarach have broad spectrum antibacterial potential. The results obtained correlated well with the report of Sen et al. ${ }^{[14]}$, in which the ethanol extract of leaves of $M$. azedarach showed antimicrobial activity against clinical pathogens such as $B$. cereus, $S$. aureus, E. coli, P. aeruginosa, A. flavus and A. niger. They also reported that ethanol extract was better compared to the aqueous extract. In this study also, ethanol extract exhibited significant antimicrobial activity compared to methanol and acetone extracts. Majeed ${ }^{[15]}$ examined the antimicrobial activity of $M$. azedarach leaves against $S$. aureus, Klebsiella sp., E. coli and P. aeruginosa. He reported that the extract showed better activity against $S$. aureus at a concentration of $100 \mu \mathrm{g} / \mathrm{ml}$ compared to other microbes used in their study. In this study, the ethanol extract exhibited significant antibacterial activity against $S$. aureus compared to Gram-negative bacteria.

Khan et al. ${ }^{[16]}$ evaluated the antibacterial activity of seed extracts of $M$. azedarach against selected human pathogenic bacteria and reported that all extracts tested revealed antibacterial potential. In their study, petrol fraction exhibited maximum inhibition against B. subtilis, Proteus mirabilis and Shigella flexneri and benzene extract inhibited the growth of twelve tested pathogens and the maximum inhibition zone was recorded against Proteus mirabilis and S. flexneri. All the tested pathogens showed sensitivity against the ethyl acetate extract and the most affected bacteria were S. aureus, B. subtilis, $P$. aeruginosa and $S$. flexneri. The methanol extract was also found to be effective against all the strains and maximum inhibition was recorded against $S$. dysenteriae and Plesiomonas shigelloides and aqueous extract showed moderate degree of activity against all tested pathogenic bacteria. Finally they concluded that the seed extracts of $M$. azedarach could be an effective antibiotic, both in controlling Gram-positive and Gram-negative human pathogens.

The ethanol extract of ripe fruits of $M$. azedarach showed fungistatic MIC from 50-300 $\mu \mathrm{g} / \mathrm{ml}$ and fungicidal MIC from $60-500 \mu \mathrm{g} / \mathrm{ml}$ against A. flavus, Fusarium moniliforme, Microsporum canis and C. albicans, respectively ${ }^{[17]}$. In the current study, the ethanol extract of leaves of $M$. azedarach showed MIC of $250 \mu \mathrm{g} / \mathrm{ml}$ against both the A. niger and C. albicans. The present study suggested that the leaves of $M$. azedarach have potential phytocompounds to kill the human fungal pathogens and it could be used for the treatment of diseases caused by these fungal pathogens.

Bioautography is a microbial detection method hyphenated with planar chromatography techniques. It is based mainly on antimicrobial or antifungal properties of analysed substances ${ }^{[18]}$. TLC-DB links separation on an adsorbent layer with biological tests performed directly on it. Therefore, the method is very convenient for searching plant constituents with biological activity, such as antibiotics. TLCDB is a high throughput method enabling analyses of many samples in parallel and the comparison of their activity. Both screening and semi-quantitative analysis is possible. The targeted compounds can be identified using spectroscopic methods, mostly mass spectrometry, that can be performed directly on a TLC plate $^{[19]}$. In this study, the phytocompounds present in the ethanol extract of $M$. azedarach was separated using TLC plate, which showed a total of 7 separation bands and the TLC plate containing phytochemical bands was further subjected to the TLC-DB. It was found that the band with $\mathrm{R}_{f}$ value of 0.9 showed significant zone 
of inhibition against $B$. subtilis. The TLC-DB analysis revealed that the band in the $\mathrm{R}_{f}=0.9$ might have the pure compounds with antibacterial activity.

Methanol extract of $M$. azedarach fruits was analysed by GC-MS and found to contain hexadecenoic, acetic and hexanoic acids as well as furfural and 5-hydroxymethylfurfural. It was found that nematocidal on Meloidogyne incognita both in terms of juveniles' paralysis and biological cycle arrest ${ }^{[20]}$. In this study, the extract showed maximum inhibitory zone against Bacillus subtilis, hence this organism was taken for TLC profiling. The TLC plate was further placed on MHA plates, swabbed with $B$. subtilis and the zones of inhibition formed were observed. The inhibition zone formed indicated clearly the antibacterial activity of the ethanolic leaf extract of $M$. azedarach. Bioautography detection was made and bands are seen at different $\mathrm{R}_{f}$ values. The band layer in that plate demonstrating activity was scrapped out and GC-MS analysis was performed to find out the exact component, which was responsible for the antibacterial activity. The active component which was present in higher amount was 5,6,7,8-tetrahydro-1,2,4-benzotriazine-3-amine. The result of the present investigation clearly demonstrated that the leaves of the medicinal plant $M$. azedarach possessed antibacterial and antifungal activity and the active component responsible for these activities could be 5,6,7,8-tetrahydro-1,2,4-benzotriazine-3-amine. Thus, this study ascertained the value of $M$. azedarach plant used in traditional medicine, which would be of considerable interest for development of a new drug based on the active component present in it as a novel chemotherapeutic agent.

\section{REFERENCES}

1. Iwu MM, Duncan AR, Okunji CO. New Antimicrobials of Plant Origin. In: Janick J, editor. Perspectives on new crops and new uses. Alexandria: Ashs Press; 1999. p. 457-62.

2. Castello M, Phatak A, Chandra N, Sharon M. Antimicrobial activity of crude extracts from plant parts and corresponding calli of F Bixa orellana L. Indian J Exp Biol 2002;40:1378-81.

3. Sujatha S. Complementary and alternative therapies in palliative care: A transition from modern medicine to traditional medicine in India. J Cancer Pain Symptom Palliation 2005; 1:25-9.

4. Westh H, Zinn CS, Rosdahl VT. An international multicenter study of antimicrobial consumption and resistance in Staphylococcus aureus isolates from 15 hospitals in 14 countries. Microb Drug Resist 2004;10:169-76.
5. Bandow JE, Brotz H, Leichert LI, Labischinski H, Hecker M. Proteomic approach to understanding antibiotic action. Antimicrob Agents Chemother 2003;47:948-55.

6. Colombo ML, Bosisio E. Pharmacological activities of Chelidomiummajus L (Paveraceae). Pharmacol Res 1996;33:127-34.

7. Beegum BN, Devi GT. Antibacterial activity of selected Seaweads from Kovalan south West coast of India. Asian J Microbiol Biotechnol Environ Sci 2003;5:319-22.

8. Kahn AV. Ethnobotanical studies on plants with medicinal and anti-bacterial properties [dissertation]. Aligarh: Aligarh Muslin University; 2002. p. 1-293.

9. Khan AV, Khan AA, Shukla I. In vitro antibacterial potential of Meliaazedarach crude leaf extracts against some human pathogenic bacterial strains. Ethnobot Leaflets 2008;12:39-45.

10. Holder IA, Boyce ST. Agar well diffusion assay testing of bacterial susceptibility to various antimicrobials in concentrations non-toxic for human cells in culture. Burns 1994;20(5):426-9.

11. National Committee for Clinical Laboratory Standards. Reference method for broth dilution antifungal susceptibility testing of yeasts. Approved standard M27-A. Wayne, Pennsylvania: National Committee for Clinical Laboratory Standards; 1997.

12. Narasimhachari N, Ramachandran S. A simple bioatuographic technique for identifying biologically active material on thinlayer chromatograms. J Chromatogr A 1967;27:494.

13. Chaurasia OP, Ahmed Z, Ballabh B. Ethnobotany and Plants of Trans-Himalaya. New Delhi: Satish Serial Publishing House; 2007.

14. Sen A, Batra A. In vivo and in vitro comparative study of total phenol content and antioxidant activity of Melia azedarach L. J Pharm Res 2012;5(1):47-50.

15. Majeed SM. Study of the Antimicrobial effect of Melia azedarach L. plant. J Biotech Res 2013;7(1):87-90.

16. Khan AV, Ahmed QU, Mir MR, Shukla I, Khan AA. Antibacterial efficacy of the seed extracts of Melia azedarach against some hospital isolated human pathogenic bacterial strains. Asian Pac J Trop Biomed 2011;1(6):452-5.

17. Carpinella MC, Herrero GG, Alonso RA, Palacios SM. Antifungal activity of Melia azedarach fruit extract. Fitoterapia 1999;70(3):296-8.

18. Choma IM, Grzelak EM. Bioautography detection in thinlayer chromatography. J Chromatogr A 2011;1218(19):268491.

19. Choma IM, Jesionek W. TLC-Direct bioautography as a high throughput method for detection of antimicrobials in plants. Chromatography 2015;2(2):225-38.

20. Caboni P, Ntalli NG, Bueno CE, Alche LE. Isolation and Chemical Characterization of Components with Biological Activity Extracted from Azadirachta indica and Melia azedarach. In: Patil BS, Jayaprakasha GK, Murthy KNC, Seeram NP, editors. Emerging Trends in Dietary Components for Preventing and Combating Disease. Washington, United States: ACS Symposium Series (ACS Publications); 2012. p. 51-77. 